\title{
Biologia reprodutiva do Hassar affinis (Pisces: Siluriformes, Doradidae), Lago de Viana, Baixada Maranhense, Maranhão, Brasil
}

\author{
Lorrane Gabrielle CANTANHÊDE ${ }^{1 *}$; Irayana Fernanda da Silva CARVALHO $^{1}$; Nayara Barbosa SANTOS ${ }^{1}$; \\ Zafira da Silva de ALMEIDA ${ }^{1}$ \\ 1 Universidade Estadual do Maranhão, Departamento de Química e Biologia, Laboratório de Pesca e Ecologia Aquática. Avenida Lourenço Vieira da Silva S/N, Tirirical, São Luís-MA, Brasil. \\ * Autora correspondente: Iorranegabrielle@hotmail.com
}

\begin{abstract}
RESUMO
O estudo da biologia reprodutiva é importante para determinar medidas protetivas visando à manutenção dos estoques pesqueiros. Desta forma, o presente estudo teve como objetivo determinar os aspectos da reprodução de Hassar affinis no Lago de Viana, Baixada Maranhense, Maranháo, Brasil. Os 147 espécimes foram provenientes da pesca comercial, coletados no período de fevereiro de 2012 a janeiro de 2013. Em laboratório, procedeu-se com a pesagem e medidas de cada indivíduo e posteriormente foi feita uma incisão ventro-longitudinal a fim de observar macroscopicamente as gônadas. Em seguida, foram fixadas em Solução de Bouin para análise microscópica e em Solução de Gilson para análise da fecundidade. A alometria negativa foi registrada para ambos os sexos, indicando maior incremento em comprimento do que em peso. A proporçáo sexual para o período total foi de 3,4 fêmeas para cada 1 macho. Houve maior intensidade reprodutiva nos bimestres fevereiro/março e abril/maio, indicando o período reprodutivo da espécie. Estima-se fecundidade absoluta média de 47.211 ovócitos. A primeira maturidade sexual é alcançada com $11,52 \mathrm{~cm}$. A partir desses dados, portanto, são sugeridas medidas de gerenciamento, como o estabelecimento do período de reprodução da espécie durante os meses de fevereiro a maio, definição do tamanho mínimo de captura de $11,5 \mathrm{~cm}$ e, além disso, sugere-se o desenvolvimento de outros trabalhos com periodicidade mensal.
\end{abstract}

PALAVRAS-CHAVE: Conservação, Peixe, Região neotropical.

\section{Reproductive biology of Hassar affinis (Pisces: Siluriformes, Doradidae), Lake of Viana, Baixada Maranhense, Maranhão Brazil}

\begin{abstract}
The study of reproductive biology is important to determine protective measures for the maintenance of fish stocks. Thus, this study aimed to determine some aspects of the reproductive biology of Hassar affinis in the Lake of Viana, at the Baixada Maranhense, Maranhão, Brazil. A total of 147 specimens were used in the study. They came from commercial fishing, collected in the period between February 2012 and January 2013. In the laboratory, they were weighed and body traits measured. A longitudinal incision was made ventrally in order to macroscopically observe the gonads. After that, they were fixed in Bouin solution for microscopic analysis and Gilson solution for analysis of fertility. Negative allometry was recorded for both genders, indicating greater increase in length than by weight. The sex ratio for the entire period was 3.4 females per 1 male. There was a greater reproductive activity in the bimesters February/March and April/May, which indicates that the reproductive period of this species occur in these months. The average absolute fecundity is estimated in 47,211 oocytes. The first sexual maturity is reached at $11.52 \mathrm{~cm}$. Based on these data, management measures are suggested, defining the reproductive for this species from February to May, and setting minimum catching size of $11.5 \mathrm{~cm}$ and, furthermore, it is suggested the development of other work at monthly intervals.
\end{abstract}

KEYWORDS: Conservation, Fish, Neotropical region. 


\section{INTRODUÇÃO}

Hassar affinis (Steindachner, 1881), popularmente conhecido por Mandi Bico-de-Flor, pertence à ordem Siluriformes, família Doradidae. Geograficamente, tem ocorrência registrada para a região amazônica, tanto em ambientes lóticos, em corredeiras de grandes rios, como em ambientes lênticos, em lagos, sendo mais frequentemente capturada no Rio Solimóes, alto e baixo Rio Xingu, Rio Tocantins, Rio Araguaia, Rio Parnaíba e Sistema Lacustre Pindaré-Mearim (Fayal 2007), sendo este último uma grande regiáo de lagos pertencente à APA da Baixada Maranhense.

Tendo em vista que há ampla ocorrência desta espécie na regiấo amazônica, o estabelecimento de regulamentação da pesca a nível regional se faz necessário, e os estudos acerca da biologia reprodutiva das espécies contribuem para a determinação de normas importantes visando à manutenção dos estoques pesqueiros.

Dentre os principais aspectos que compóem a biologia reprodutiva das espécies de peixes, destacam-se o tamanho de primeira maturação sexual, período reprodutivo e fecundidade. $\mathrm{O}$ entendimento de tais parâmetros pode ser considerado como o primeiro passo para o estabelecimento dos principais padróes da história de vida de peixes (Mazzoni e Silva 2006). Segundo Vazzoler e Menezes (1992), entender as táticas e estratégias reprodutivas é elemento imprescindível para nortear as medidas de administração, manejo e preservação da ictiofauna frente aos impactos ocasionados por ações antrópicas como a pesca e a eliminação de áreas de desova e de criadouros.

$\mathrm{O}$ comprimento médio em que os indivíduos atingem a maturidade sexual é importante para gerenciar eficazmente uma população explorada, uma vez que pode ser usado para determinar um tamanho mínimo permissível de captura (King 1997). O estudo do desenvolvimento gonadal dos peixes sáo importantes quando se pretende conservar os estoques pesqueiros, pois fornecem conhecimentos básicos para determinar o período reprodutivo de uma espécie (Cavalcante et al. 2012). A fecundidade é um aspecto importante para a manutenção dos estoques pesqueiros, pois indica a capacidade da espécie de se reproduzir em diversos ciclos e com sucesso durante a sua vida, conservando populaçôes viáveis (Marques et al. 2001).

Os aspectos reprodutivos citados, para a regiáo em estudo, sáo desconhecidos ou desatualizados tanto para a espécie em questáo, como para tantas outras que existem na área, o que a médio-longo prazo pode resultar em sobreexplotação pesqueira, já que boa parte apresenta importância comercial e sáo utilizadas sem nenhum tipo de controle ou gerenciamento. Desta forma, o presente estudo teve como objetivo determinar os aspectos da reprodução de Hassar affinis no Lago de Viana, APA da Baixada Maranhense.

\section{MATERIAL E MÉTODOS}

\section{Obtenção de dados}

O Lago de Viana (0314'08”'S; 4505'09”W) localizado no município de Viana, Baixada Maranhense (Figura 1), foi escolhido com base no fato de ser um lago de várzea, formado pela inundação das águas do rio Pindaré, afluente da margem esquerda do rio Mearim (Piorski et al. 2005) e por possuir importância econômica e ecológica para os nativos além de ser área de vida de uma grande diversidade íctica, necessitando de medidas protetivas.

Os exemplares foram coletados bimestralmente entre o período de fevereiro de 2012 a janeiro de 2013, no Lago de Viana, utilizando redes de espera com tamanho de malha de 50, 60 e $70 \mathrm{~mm}$ entre nós opostos. Exemplares testemunhos estâo depositados na coleçáo ictiológica do Laboratório de Pesca e Ecologia Aquática da Universidade Estadual do Maranhão (UEMA).

Em laboratório, registrou-se o comprimento total, comprimento padrão, comprimento furcal em centímetros (1 $\mathrm{cm}$ de precisão), peso total, peso do eviscerado, peso de vísceras em gramas ( $0,01 \mathrm{~g}$ de precisão), sexo e estádio maturacional.

\section{Análise de dados}

Os estádios maturacionais e o sexo de $H$. affinis foram determinados através de análises macroscópicas e confirmados com análise histológica quando necessário. Em cada exemplar foi realizada uma secçáo ventro-longitudinal para extração das gônadas e identificação macroscópica, observando-se algumas características como: cor, vascularização, volume em relação à cavidade abdominal, irrigação sanguínea, visibilidade dos ovócitos, presença de esperma e sua consistência. Uma escala de maturaçáo previamente estabelecida foi utilizada para classificação macroscópica das gônadas, conforme as seguintes categorias: $\mathrm{A}=$ imaturo; $\mathrm{B}=$ em maturação; $\mathrm{C}=$ maturo e $\mathrm{D}$ = desovado/esvaziado (Vazzoler 1996). Em seguida foram pesadas em balança de precisão de $0,01 \mathrm{~g}$.

Quando não foi possível determinar o estádio a nível macroscópico, as gônadas passaram por análise microscópica, seguindo as técnicas histológicas eventuais, fixadas em Bouin, com inclusão em parafina e coloração com hematoxilina-eosina.

A relaçáo entre comprimento total e peso total foi estabelecida através da regressão não linear. $\mathrm{O}$ ajuste da curva representada pela expressão matemática, $\mathrm{WT}=\mathrm{a} \times \mathrm{LT}^{b}$, foi obtida pelo método dos mínimos quadrados sugerido por Zar (1996), onde WT é o peso total do peixe, a é o coeficiente linear de regressão, LT é o comprimento total do peixe e b é o coeficiente angular de regressão.

A proporção sexual dos indivíduos amostrados foi obtida para o período total, por classes de comprimento e por bimestre. Para verificar a existência de diferenças significativas 


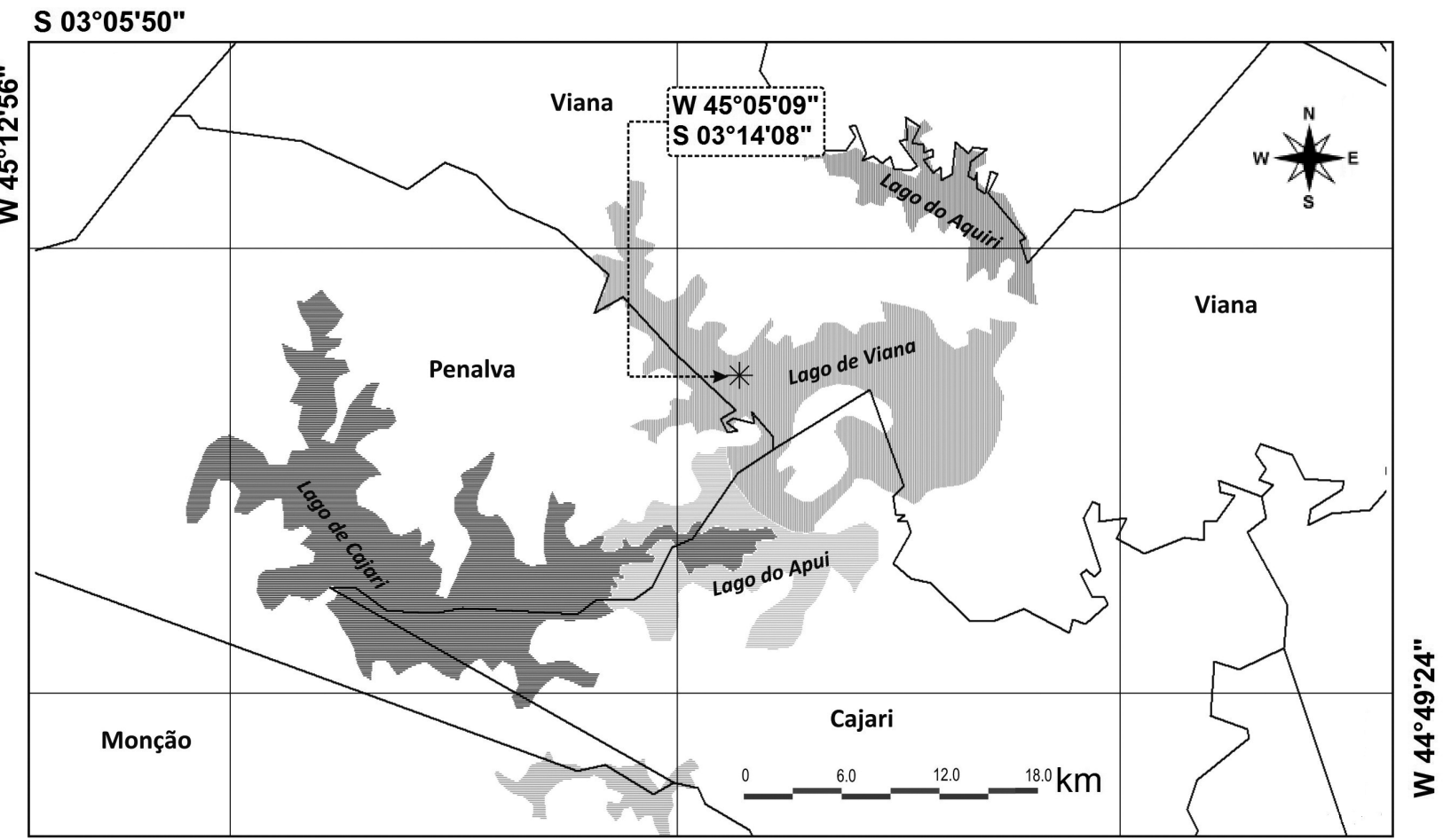

$S 03^{\circ} 25^{\prime} 22^{\prime \prime}$

Figura 1. Mapa de localização do Lago de Viana, Viana, Maranhão, Brasil. Simbologia: 0 asterisco $\left(^{*}\right)$ indica o Lago de Viana e 0 traço (-) indica os limites municipais.

na proporção entre os sexos foi utilizado o teste do $\chi^{2}$ (quiquadrado) com correção de Yates e nível de significância de 5 $\%$ definido pela equação.

Para a análise do tamanho da primeira maturaçáo (L50), os estádios maturacionais foram agrupados em imaturos (estádio A) e em maturos (estádios $\mathrm{B}+\mathrm{C}+\mathrm{D}$ ), seguindo o proposto por Vazzoler (1996) e Ortiz-Ordónez et al. (2007). O percentual de maturos por classe de comprimento foi calculado e considerado como variável dependente $(\mathrm{Y})$ e o comprimento total como variável independente $(\mathrm{X})$. Posteriormente, estes valores foram ajustados a uma curva logística utilizando o software Statistica, versão 7.0, sob licença do Laboratório de Pesca e Ecologia Aquática (UEMA), segundo a fórmula: $\mathrm{P}=1$ / $(1+\exp [-\mathrm{r}(\mathrm{LT}-\mathrm{L} 50)])$, onde: $\mathrm{P}=$ proporção de indivíduos maturos; $r$ = declive da curva; $\mathrm{LT}=$ Comprimento total; $\mathrm{L} 50$ = comprimento médio de maturidade sexual.

O período reprodutivo foi definido com base na frequência bimestral dos estádios de maturidade e pela variação dos valores médios da relação gonadossomática ( $\triangle \mathrm{RGS}$ ) e do fator de condição $(\Delta K)$.

A relação gonadossomática ( $\triangle \mathrm{RGS}$ ) é a diferença entre

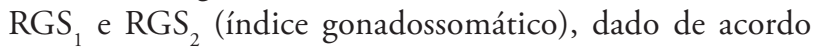
com as fórmulas:

$\mathrm{RGS1}=(\mathrm{Wg} / \mathrm{WT}) \mathrm{x} 100$

\section{RGS2 $=(\mathrm{Wg} / \mathrm{Wc}) \times 100$}

Onde: $\mathrm{Wg}=$ peso da gônada; $\mathrm{WT}=$ peso total do indivíduo; $\mathrm{Wc}_{\mathrm{c}}=\mathrm{WT}-\mathrm{Wg}$.

O fator de condição $(\Delta \mathrm{K})$ é a diferença entre os dois modelos $\mathrm{K}_{1}$ e $\mathrm{K}_{2}$ (índices do fator de condição alométrico), dado de acordo com as fórmulas:

$$
\begin{aligned}
& \mathrm{K}_{1}=\mathrm{WT} / \mathrm{LTb} \\
& \mathrm{K}_{2}=\mathrm{WC} / \mathrm{LTb}
\end{aligned}
$$

Onde: $\mathrm{K}_{1}$ = fator de condição total; $\mathrm{K}_{2}=$ fator de condição somático; $\mathrm{WT}$ = peso total do indivíduo; $\mathrm{LT}$ = comprimento total do indivíduo; $\mathrm{b}=$ coeficiente angular da relaçáo peso/ comprimento; $\mathrm{WC}=\mathrm{WT}-\mathrm{Wg}$, em que: $\mathrm{Wg}=$ peso da gônada.

A fecundidade (F) foi estimada pelo método volumétrico segundo Vazzoler (1996). Dez gônadas foram selecionadas e colocadas em solução de Gilson modificada (Simpson 1951) para dissociaçáo dos ovócitos. Posteriormente, foi registrado o volume total dos ovócitos e extraídas três subamostras. A fecundidade relativa foi estabelecida através da relação entre comprimento total (LT), peso total (WT) e fecundidade (F), expressas pelas equaçôes: $\mathrm{FR}=\mathrm{a} \times \mathrm{LT}^{\mathrm{b}} \mathrm{e} \mathrm{FR}=\mathrm{a} \times \mathrm{WT}^{\mathrm{b}}$, onde: FR é a fecundidade relativa; LT, o comprimento total; WT, o peso total; a, o coeficiente linear da regressão; e b, o coeficiente angular da regressão. A análise de correlação da fecundidade 
tanto com o peso quanto com o comprimento foi realizada pelo coeficiente de correlação de Pearson.

O tipo de desova foi definido com base na observaçáo da frequência de ovócitos de cada intervalo de diâmetro e o padrão encontrado foi comparado com a relaçấo gonadossomática, fator de condição e frequência dos estádios maturacionais.

\section{RESULTADOS}

Foram analisados 147 exemplares de $H$. affinis com comprimento total entre 10 e $21 \mathrm{~cm}$. Durante o período seco (Julho a Dezembro), ocorreram 34 fêmeas e 11 machos e, durante o período chuvoso (Janeiro a Julho), ocorreram 79 fêmeas e 23 machos distribuídos em todas as classes de comprimento totalizando 113 fêmeas e 34 machos analisados (Figura 2). Nas coletas realizadas durante o período seco, a espécie não ocorreu no lago por dois bimestres, Junho/Julho e Agosto/Setembro, ocasionando as diferenças de amostragem observadas entre os dois períodos. O peso mínimo observado foi de $16 \mathrm{~g}$ e o máximo de $120 \mathrm{~g}$, gerando uma média de $45 \mathrm{~g} \pm 17 \mathrm{~g}$.

Quanto à proporção sexual, houve predomínio evidente de fêmeas tanto no período seco (Julho a Dezembro) (3,09F:1M) $\left(\chi^{2}=11,75 ; \mathrm{df}=1 ; \mathrm{p}<0,05\right)$ quanto no período chuvoso (Janeiro a Julho) $(3,43 \mathrm{~F}: 1 \mathrm{M})\left(\chi^{2}=30,74 ; \mathrm{df}=1 ; \mathrm{p}<0,05\right)$. A proporçáo sexual para o período total foi de $3,32 \mathrm{~F}: 1 \mathrm{M}\left(\chi^{2}\right.$ $=42,45 ; \mathrm{df}=1 ; \mathrm{p}<0,05) . \mathrm{O}$ teste do $\chi^{2}$ demonstrou haver diferenças significativas entre machos e fêmeas nos três casos.

As fêmeas predominaram em quase todos os bimestres, com exceção do bimestre abril/maio em que houve um número maior de exemplares machos. Contudo, apesar desta predominância, o teste do $\chi^{2}(2,11, \mathrm{df}=1 ; \mathrm{p}>0,05)$ indicou que não houve diferenças significativas entre os sexos para este bimestre, ao contrário dos bimestres onde as fêmeas foram predominantes. $\mathrm{O}$ teste do $\chi^{2}$ demonstrou que para todas as classes de comprimento, com exceção de 10-12 cm e 20-22 cm, houve diferenças significativas entre os sexos com predominância de fêmeas. O comprimento total dos indivíduos capturados variou de 12,1 a $21,0 \mathrm{~cm}$ para fêmeas com valores médios de $15,37 \mathrm{~cm} \pm 1,82 \mathrm{~cm}$ e de 10,0 a 18,1 $\mathrm{cm}$ para machos com valores médios de $14,11 \mathrm{~cm} \pm 1,56 \mathrm{~cm}$. A alometria negativa foi registrada para ambos os sexos, indicando que a espécie no local estudado está ganhando mais incremento em comprimento do que em peso. $\mathrm{O}$ coeficiente angular de regressão (b) não apresentou diferenças significativas entre machos e fêmeas $(t=3,21 ; \mathrm{df}=1 ; \mathrm{p}>0,05)$ (Tabela 1).

A avaliação macroscópica dos ovários permitiu constatar a presença de indivíduos de $H$. affinis nos quatro estádios maturacionais: Estádio A, B, C e D (Figura 3 e Tabela 2), visualizados através de lâminas histológicas (Figura 4).

Entre os exemplares analisados, ocorreu um alto índice de indivíduos em estágio C (maturo) durante o período chuvoso, coincidindo com os maiores picos pluviométricos, nos bimestres dezembro/janeiro, fevereiro/março e abril/maio (Figura 5). Os valores médios de $\Delta$ RGS e $\Delta \mathrm{K}$ para fêmeas de $H$. affinis coincidiram tanto nos picos quanto nas quedas, para os bimestres amostrados. A relação gonadossomática ( $\triangle$ RGS) indica a maturação das células reprodutivas ocorrendo concomitantemente com o aumento do peso das gônadas, e a coincidência com o período de maiores picos no fator

Tabela 1. Parâmetros da relação peso-comprimento para machos e fêmeas de $H$. affinis, no período de fevereiro/2012 a janeiro/2013, no Lago de Viana, Baixada Maranhense, Maranhão, Brasil. $(n=$ número de indivíduos; $\mathrm{LT}=$ comprimento; $A=$ coeficiente linear; $b=$ coeficiente de regressão; $r^{2}=$ coeficiente de determinação).

\begin{tabular}{lcccccc}
\hline & $\mathrm{n}$ & $\begin{array}{c}\mathrm{CT}(\text { Min-Max }) \\
(\mathrm{cm})\end{array}$ & $\mathrm{A}$ & $\mathrm{b}$ & $\mathrm{r}^{2}$ & Alometria \\
\hline Fêmeas & 113 & $12,1-21,0$ & 0,0201 & 2,8275 & 0,88 & Negativa \\
Machos & 34 & $10,0-18,1$ & 0,078 & 2,3157 & 0,57 & Negativa \\
\hline
\end{tabular}
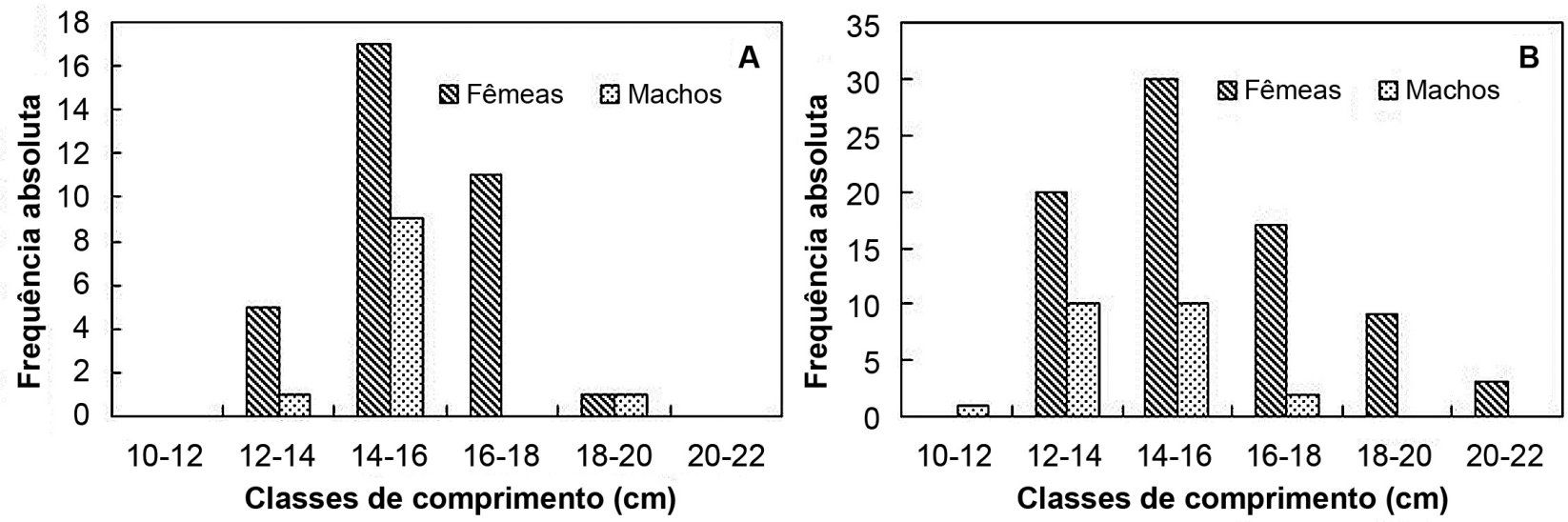

Figura 2. Estrutura da população de H. affinis por período sazonal do ano. A: seco; B: chuvoso, no Lago de Viana, Baixada Maranhense, Maranhão, Brasil. 

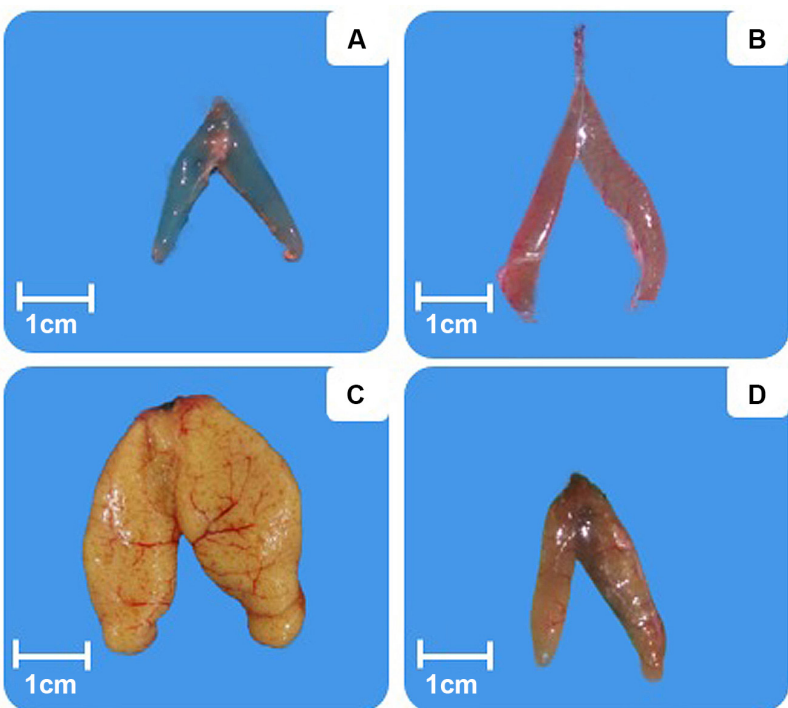

Figura 3. Gônadas nos estádios maturacionais de exemplares fêmeas de H. affinis: A: imaturo; B: em maturação; C: maturo; D: desovado, no Lago de Viana, Baixada Maranhense, Maranhão, Brasil. (Esta figura é colorida na versão eletrônica).

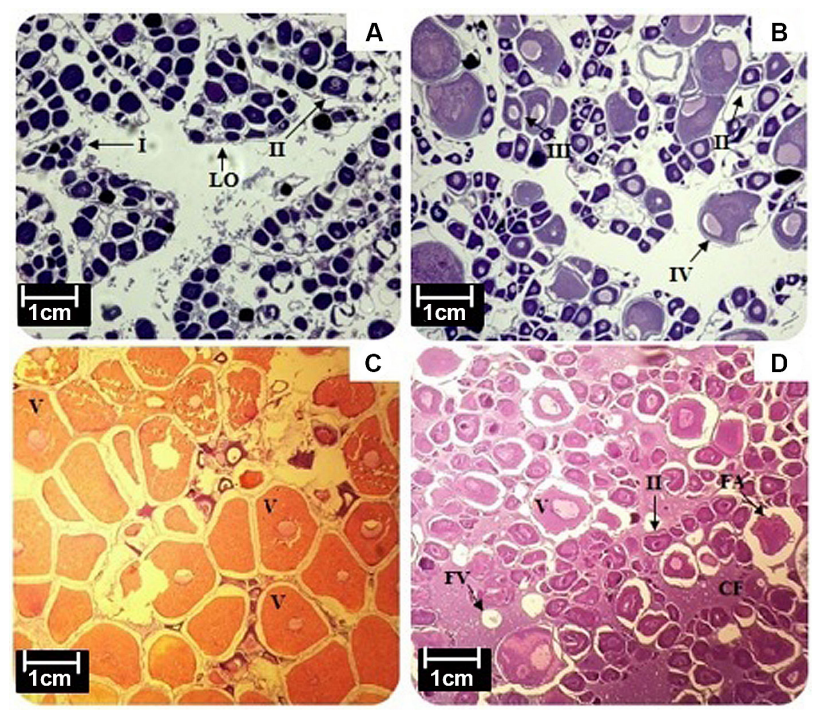

Figura 4. Fotomicrografia dos ovários de $H$. affinis durante o ciclo gonadal. A: Ovário imaturo; B: Ovário em maturação; C: Ovário maturo; D: Ovário desovado. HE 100x. (I: Fase de cromatina nucléolo; II: ovócitos de estoque de reserva; III: ovócitos com vitelogênese lipídica; IV: ovócitos com vitelogênese lipídica e protéica; V: ovócitos com vitelogênese completa; LO: Lamelas ovígeras; FV: Folículo vazio; FA: Folículo atrésico; CF: Corpos foliculares), no Lago de Viana, Baixada Maranhense, Maranhão, Brasil. (Esta figura é colorida na versão eletrônica).

de condição, que indica o bem-estar da espécie, demonstra a aptidão da espécie para desovar neste período (Figura 6).

Quanto ao tipo de desova, o diâmetro variou de $150 \mu \mathrm{m}$ a $650 \mu \mathrm{m}$, havendo uma menor frequência de ovócitos medindo
Tabela 2. Correlação entre os estágios macro e microscópios das gônadas de fêmeas de H. affinis, no Lago de Viana, Baixada Maranhense, Maranhão, Brasil.

\begin{tabular}{|c|c|c|c|c|}
\hline \multirow{2}{*}{ Características } & \multicolumn{4}{|c|}{ Classificação proposta } \\
\hline & Imaturo & Em maturação & Maturo & Desovado \\
\hline \multicolumn{5}{|l|}{$\begin{array}{l}\text { Aspectos } \\
\text { macroscópicos }\end{array}$} \\
\hline & & & & \\
\hline $\begin{array}{l}\text { em relação } \\
\text { à cavidade } \\
\text { abdominal }\end{array}$ & $<1 / 4$ & $1 / 2-1 / 3$ & $3 / 4-4 / 4$ & $1 / 3-1 / 2$ \\
\hline $\begin{array}{l}\text { Percepção dos } \\
\text { ovócitos }\end{array}$ & Não & Poucos & Sim & Poucos \\
\hline $\begin{array}{l}\text { Aspectos dos } \\
\text { ovócitos }\end{array}$ & - & $\begin{array}{c}\text { Esbranquiçados } \\
\text { e pequenos }\end{array}$ & $\begin{array}{l}\text { Amarelados } \\
\text { e grandes }\end{array}$ & $\begin{array}{l}\text { Amarelados } \\
\text { e grandes }\end{array}$ \\
\hline Vascularização & Não & $\begin{array}{l}\text { Maior que na } \\
\text { fase anterior }\end{array}$ & Elevada & Hemorrágico \\
\hline $\begin{array}{l}\text { Coloração das } \\
\text { gônadas }\end{array}$ & Translúcidas & $\begin{array}{l}\text { Amarelo/ } \\
\text { Marrom }\end{array}$ & Amarelo & Vermelhas \\
\hline $\begin{array}{l}\text { Tipos de } \\
\text { ovócitos } \\
\text { predominantes }\end{array}$ & $\begin{array}{l}\text { Fase I e } \\
\text { II; LO }\end{array}$ & Fase II, III e IV & Fase IV e V & $\begin{array}{c}\text { II, V, CF, FV, } \\
\text { FA }\end{array}$ \\
\hline
\end{tabular}

I: Fase de cromatina nucléolo; II: ovócitos de estoque de reserva; Ill: ovócitos com vitelogênese lipídica; IV: ovócitos com vitelogênese lipídica e protéica; V: ovócitos com vitelogênese completa; LO: Lamelas ovígeras; FV: Folículo vazio; FA: Folículo atrésico; CF: Corpos foliculares

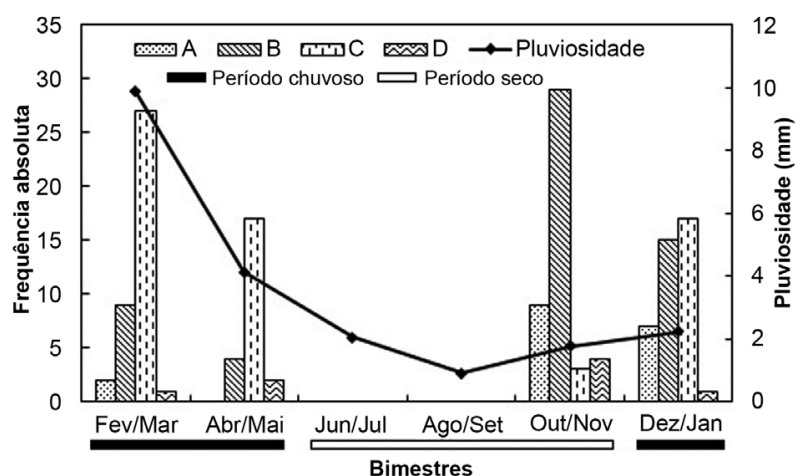

Figura 5. Frequência relativa bimestral dos estádios maturacionais de machos e fêmeas de H. affinis. A: imaturo; B: em maturação; C: maturo; D: desovado/ esvaziado, no Lago de Viana, Baixada Maranhense, Maranhão, Brasil.

entre $150 \mu \mathrm{m}$ a $350 \mu \mathrm{m}$ e uma maior frequência de ovócitos medindo entre $351 \mu \mathrm{m}$ a $650 \mu \mathrm{m}$. Desta forma, foi possível destacar dois grupos principais, divididos em duas modas. $\mathrm{Na}$ moda I, os ovócitos mediram entre $150 \mu \mathrm{m}$ e $350 \mu \mathrm{m}$, porém ainda não vitelogênicos e na moda II, os ovócitos vitelogênicos, medindo entre $351 \mu \mathrm{m}$ e $650 \mu \mathrm{m}$, aptos a serem desovados. Logo, o tipo de desova foi definido como sincrônico em dois grupos e total.

O tamanho de primeira maturação sexual de $H$. affinis, para fêmeas foi de $11,56 \mathrm{~cm}$, para machos de $11,46 \mathrm{~cm}$ e para sexos agrupados de $11,52 \mathrm{~cm}$.

O número de ovócitos encontrados variou entre 23.243 e 72.242, que resultou em uma fecundidade absoluta média 

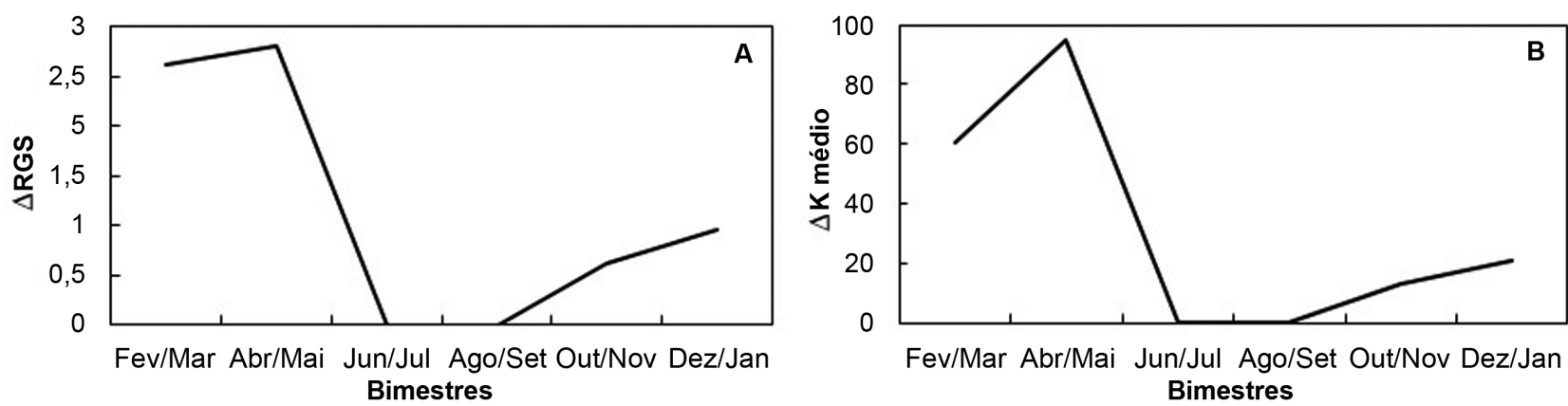

Figura 6. A: Valores médios de $\triangle R G S$ das fêmeas de $H$. affinis; B: Valores médios de $\Delta K$ das fêmeas de $H$. affinis, no Lago de Viana, Baixada Maranhense, Maranhão, Brasil.

(FA), representada por aqueles ovócitos que, potencialmente, seriam eliminados na próxima desova de 47.211 ovócitos \pm 16.741 .

A fecundidade relativa média (FR) resultou em 3.777 ovócitos por centímetro de comprimento total e 1.170 ovócitos por grama de peso total da fêmea. O coeficiente de correlação de Pearson indicou uma forte correlaçáo para comprimento $(r=0,95)$ e uma fraca correlaçáo para peso $(r=0,20)$.

\section{DISCUSSÃO}

Os maiores picos reprodutivos, com indivíduos no estágio maturo, foram registrados no mesmo período em que houve os maiores picos pluviométricos, maiores picos na relaçáo gonadossomática e fator de condição indicando que as chuvas influenciam diretamente na reproduçáo desta espécie para o local estudado.

$\mathrm{Na}$ Amazônia Central a reprodução dos peixes tem sido mencionada como estreitamente relacionada com a flutuação do nível d'água, que apresenta média anual em torno de 10 $\mathrm{m}$, regulando o ciclo biológico dos peixes principalmente no desenvolvimento dos órgáos sexuais, sendo considerado grande estímulo para o desencadeamento da desova (Santos 1982; Leão et al. 1991).

Essas condiçôes normalmente estão associadas ao início da época de chuvas e da alagação quando a alta disponibilidade de alimento favorece o desenvolvimento e crescimento das larvas e juvenis (Menezes e Vazzoler 1992; Sánchez-Botero e Araújo-Lima 2001; Leite et al. 2006).

Visto que a espécie apresentou um segundo pico de indivíduos maturos em dezembro/janeiro, com células em dois estágios diferentes, é esperado que a desova ocorra mais de uma vez ao longo do ano. Este tipo de desova representa certa vantagem em caso de impactos ambientais, pois garante novas oportunidades de reprodução para a espécie.

A proporção sexual encontrada para $H$. affinis foi de 3,32 fêmeas para cada 1 macho. Fávaro et al. (2005) também constataram para Cathorops spixi, um Siluriformes, o predomínio de fêmeas sobre machos em uma relação aproximada de quatro fêmeas para cada macho (4:1), valor aproximado ao encontrado para $H$. affinis.

Nas classes de maior comprimento houve predomínio de fêmeas, o que indica um claro dimorfismo sexual de tamanho para a espécie. Fêmeas são maiores que machos, particularmente entre os peixes, porque a fertilidade das fêmeas aumenta com o tamanho do corpo (Clutton-Brock et al. 1985; Parker 1992; Biazza e Pilastro 1997).

Anualmente o Ministério do Meio Ambiente, através do IBAMA, emite uma portaria decretando um período de defeso, exigindo a proteção das espécies durante os períodos de reprodução, e que para as bacias e sistemas lacustres do estado do Maranhão, se estende de $1^{\circ}$ de dezembro a 30 de março (IBAMA 2003). Os resultados deste estudo demonstram que o período de defeso estabelecido na regulamentaçáo coincide com os maiores picos reprodutivos da espécie e inclui o bimestre de maior pico, fevereiro e março. Este resultado demonstra a importância de trabalhos acerca da reprodução dos peixes, a fim de garantir o correto ordenamento pesqueiro para a regiáo, porém estudos reprodutivos para outras espécies da região são necessários para garantir que o período de defeso seja definido com base nos resultados da maioria.

A respeito do comprimento médio de início da primeira maturação sexual, foi possível constatar que indivíduos da espécie $H$. affinis estão sendo capturados com tamanhos inferiores ao tamanho médio do início de sua maturação sexual, o que pode significar um perigo potencial de sobrepesca de crescimento (Camargo e Lima Junior 2007).

Santos et al. (1984) relataram que a maturidade sexual para Hassar wilderi é atingida com aproximadamente 15 $\mathrm{cm}$ de comprimento. O fato da primeira maturidade sexual encontrada para $H$. affinis no Lago de Viana ser menor que o encontrado na literatura para espécies do mesmo gênero, pode dever-se aos tipos de artes de pesca utilizadas durante muito tempo pelos pescadores locais, como redes de arrasto e 
de captura com pequenos tamanhos de abertura nas malhas, tornando-se altamente predatórias. Esta condição precisa ser regulamentada com maior esforço de supervisão por parte das autoridades responsáveis no que diz respeito ao tamanho das malhas utilizadas, de forma a evitar a captura de indivíduos menores que o tamanho mínimo de captura.

A fecundidade absoluta média (FA), representada por aqueles ovócitos que, potencialmente, seriam eliminados na próxima desova, foi estimada em 47.211 ovócitos, indicando que $H$. affinis é uma espécie que apresenta alta fecundidade. A fecundidade elevada é uma característica de peixes que apresentam ovos livres e que não apresentam cuidado parental. Esta característica representa uma vantagem em uma eventual necessidade de recuperaçáo de estoques.

A grande divergência entre as quantidades de espécimes adquiridos durante o período seco e chuvoso aconteceu, provavelmente, por um fenômeno de migração da espécie durante o período seco, devido ao fato do Lago de Viana apresentar condiçóes críticas de níveis de água e consequentemente de alimento, levando a populaçáo de $H$. affinis a se deslocar para lagos vizinhos, como o Lago Aquiri e o Lago de Penalva. Estes dois lagos apresentam barragens, e estas poderiam ser responsáveis pela contençấo da população durante boa parte do período seco, explicando sua ausência durante os bimestres Junho/Julho e Agosto/Setembro, retornando somente durante o período chuvoso, onde a água transborda pela barragem, possibilitando o retorno da populaçáo de peixes aptos a desovar. Desta forma, levando-se em conta que o Lago de Viana representa um local de desova de H. affinis e, provavelmente, de outras espécies, é necessário pensar um modelo de sustentabilidade que atenda de forma satisfatória toda a bacia.

\section{CONCLUSÃO}

A variação da RGS assim como do fator de condição podem ser, nesta regiáo, utilizados como indicativo para a(s) época(s) de desova; $50 \%$ da população de $H$. affinis, encontrase adulta com cerca de $11,52 \mathrm{~cm}$ de comprimento total (L50), sendo assim, necessário monitorar os tamanhos das malhas das artes de pesca utilizadas de forma a evitar a captura de indivíduos menores que este tamanho; esta espécie possui dois picos de desova, sendo os maiores durante o período chuvoso (fevereiro a maio) indicando clara relaçáo entre a pluviosidade e o período reprodutivo e coincidindo com o estabelecido pela portaria do IBAMA acerca do período de defeso para a região. Sugere-se ainda novos estudos sobre a reprodução desta espécie, com periodicidade mensal, a fim de fornecer dados mais precisos, principalmente acerca do período de desova, e o estudo da reprodução de outras espécies da regiáo para garantir o correto ordenamento pesqueiro.

\section{AGRADECIMENTOS}

Os autores agradecem à Fundação de Amparo à Pesquisa e ao Desenvolvimento Científico e Tecnológico do Maranhão - FAPEMA pelo apoio financeiro, através do edital 022/2012, ao Laboratório de Pesca e Ecologia Aquática - LabPEA (UEMA) pela estrutura, e a todos que de alguma forma colaboraram com este trabalho, em especial a Wallacy Borges Teixeira Silva por todo o auxílio nas análises e ao professor Jucivan Lopes pela confecção do mapa.

\section{BIBLIOGRAFIA CITADA}

Biazza, A.; Pilastro, A. 1997. Small male mating advantage and reverse size dimorphism in poecillid fishes. Journal of Fish Biology, 50: 397-406.

Camargo, M.; Lima Jr, W.M.A. 2007. Aspectos da biologia reprodutiva de seis espécies de peixes. Uakari, 3: 64-77.

Cavalcante, L. de F.de M.; Oliveira, M.R.; Chellappa, S. 2012. Aspectos reprodutivos do ariacó, Lutjanus synagris nas águas costeiras do Rio Grande do Norte. Biota Amazônia, 2: 45-50.

Clutton-Brock, T.H.; Albon, S.D.; Guinness, F.E. 1985. Parental investment and sex differences in juvenile mortality in birds and mammals. Nature, 313: 131-133.

Fávaro, L.F.; Frehse, F. de A.; Oliveira, R. N de; Schwarz Júnior, R. 2005. Reprodução do bagre amarelo, Cathorops spixii (Agassiz) (Siluriformes, Ariidae), da Baía de Pinheiros, região estuarina do litoral do Paraná, Brasil. Revista Brasileira de Zoologia, 22: $1022-1029$.

Fayal, D.F. 2007. Revisão taxonômica do gênero Hassar Eigenmann \& Eigenmann, 1888, com a descriçâo osteológica de Hassar orestis (Steindachner, 1875) (Siluriformes, Doradidae). Dissertação de mestrado, Universidade Federal do Pará, Museu Paraense Emílio Goeldi, Belém, Pará. 93 p.

IBAMA- Instituto Brasileiro do Meio Ambiente e dos Recursos Naturais Renováveis. 2003. Portaria IBAMA N 85, de 31 de Dezembro de 2003 - Proibição da pesca em épocas de reprodução (http://www.mma.gov.br). Acesso em 15/10/2015.

King, M.G. 1997. Fisheries biology, assesment and management. Osney Mead, Oxford, England: Fishing news books, 341 p.

Leão, E.L.M.; Leite, R.G.; Chaves, P.T.C.; Ferraz, R. 1991. Aspectos da reprodução, alimentação e parasitofauna de uma espécie rara de piranha, Serrassalmus altuvei Ramirez, 1965 (Pisces, Serrasalmidae) do baixo rio Negro. Revista Brasileira de Biologia, 51:545-553.

Leite, R.G.; Silva, J.V.V.; Freitas, C.E. 2006. Abundância e distribuição das larvas de peixes no Lago Catalão e no encontro dos rios Solimóes e Negro, Amazonas, Brasil. Acta Amazonica, 36: $557-562$.

Marques, D. K. S.; Gurgel, H. C. B.; Lucena, I. 2001. Época de reprodução de Hoplias malabaricus Bloch, 1794 (Osteichthyes, Erythrinidae) da barragem do rio Gramame, Alhandra, Paraíba, Brasil. Revista Brasileira de Zoociências, 3: 61-67.

Mazzoni, R.; Silva, A.P.F. 2006. Aspectos da história de vida de Bryconamericus microcephalus (Miranda Ribeiro) (Characiformes, 
Characidae) de um riacho costeiro de Mata Atlântica, Ilha Grande, Rio de Janeiro, Brasil. Revista Brasileira de Zoologia, 23: 228-23.

Menezes, N.A.; Vazzoler, A.E.A. 1992. Reproductive characteristics of Characiformes. In: Hamlett, W.C. (Ed.) Reproductive biology of South American vertebrates: aquatic and terrestrial. SpringerVerlag, New York, p.60-70.

Ortiz-Ordónez, E.; Uría Galicia1, E.; López-López, E.; Maya, J.P.; Carvajal Hernández, A.L. 2007. Reproductive cycle by histological characterization of the ovary in the butterfly goodeid Ameca splendens from the upper Rio Ameca Basin, México. Journal of Applied Ichthyology, 23: 40-45.

Parker, G. A. 1992. The evolution of sexual size dimorphism in fish. Journal of Fish Biology, 41: 1-20.

Piorski, N.M; Alves, J.R.L.; Machado, M.R.B.; Correia, M.M.F. 2005. Alimentação e ecomorfologia de duas espécies de piranhas (Characiformes: Characidae) do Lago de Viana, estado do Maranhão, nordeste do Brasil. Acta Amazonica, 35: 63-70.

Sánchez-Botero, J.I.; Araújo-Lima, A.C.R.M. 2001. As macrófitas aquáticas como berçário para a ictiofauna da várzea do rio Amazonas. Acta Amazonica, 31:437-447.
Santos, G.M. 1982. Caracterização, hábitos alimentares e reprodutivos de quatro espécies de "aracus" e consideraçóes sobre o grupo no lago Janauacá, AM (Osteichthyes, Characoidei, Anostomidae). Acta Amazonica, 12:713-739.

Santos, G. M.; Jegu, M.; Merona, B. de. 1984. Catálogo de Peixes comerciais do baixo rio Tocantins. 1. ed. ELETRONORTE/ CNPqIINPA, Manaus, 86p.

Simpson, A.C. 1951. The fecundity of the plaice. Fishery Investigation, 5: 1-27.

Vazzoler, A.E.A.M.; Menezes, N.A. 1992. Síntese do conhecimento sobre o comportamento reprodutivo dos Characiformes da América do Sul (Teleostei, Ostariophysi). Revista Brasileira de Biologia, 52: 627-640.

Vazzoler, A.E.A. de M. 1996. Biologia da Reprodução dos Teleósteos: teoria e prática. SBI/EDUEM, São Paulo, 169 p.

Zar, J.H. 1996. Biostatistical analysis. 3ed. Ed. Prentice-Hall International INC, New Jersey, 662 p.

Recebido em 01/09/2015

Aceito em 24/12/2015 